\title{
A Novel Method of Sustainability Evaluation in Machining Processes
}

\author{
Haiming Sun ${ }^{1,2}$, Conghu Liu ${ }^{3, *}$, Jianqing Chen ${ }^{2,4}$, Mengdi Gao ${ }^{2,3}$ and Xuehong Shen 5 \\ 1 School of Mechanical Engineering, Hubei University of Automotive Technology, Shiyan 442002, China; \\ stephen_110@tom.com \\ 2 School of Mechanical Engineering, Hefei University of Technology, Hefei 30009, China; \\ chenjq@zjhu.edu.cn (J.C.); mengdgao@163.com (M.G.) \\ 3 School of Mechanical and Electronic Engineering, Suzhou University, Suzhou 234000, China \\ 4 QiuZhen School, Huzhou University, Huzhou 313000, China \\ 5 Xiangyang Road and Bridge Construction Group Co., Ltd., Xiangyang 441057, China; xiaobai6570@126.com \\ * Correspondence: 1ch339@126.com
}

Received: 12 March 2019; Accepted: 4 May 2019; Published: 9 May 2019

\begin{abstract}
In order to quantitatively evaluate and improve the sustainability of machining systems, this paper presents an emergy (the amount of energy consumed in direct and indirect transformations to make a product or service) based sustainability evaluation and improvement method for machining systems, contributing to the improvement of energy efficiency, resource efficiency and environmental performance, and realizing the sustainability development. First, the driver and challenge are studied, and the scope and hypothesis of the sustainable machining system are illustrated. Then, the emergy-based conversion efficiency model is proposed, which are (1) effective emergy utilization rate (EEUR), (2) emergy efficiency of unit product (EEUP) and (3) emergy conversion efficiency (ECE), to measure and evaluate the sustainable machining system from the perspectives of energy, resource and environment. Finally, the proposed model is applied to a vehicle-bridge machining process, and the results show that this paper provides the theoretical and method support for evaluating and improving the sustainable machining processes to decouple the resources and development of the manufacturing industry.
\end{abstract}

Keywords: emergy; conversion efficiency; sustainability; machining process

\section{Introduction}

Manufacturing industry, as an important part of the national industry, consumes a large portion of energy in the total energy consumption [1], and also results in serious environmental pollution in the transformation process from manufacturing resources to products [2]. The investigation shows that energy consumption of the United States is the largest, and energy consumption of its manufacturing industry accounts for about $20 \%$ of the total, S. Korea accounts for about $55 \%$ [3]. In China, energy consumption of the manufacturing industry occupies about $70 \%$ of the total [4]. It can be found that the energy consumption of any manufacturing industry is enormous and incredible [5].

In 2012, the U.S. energy information administration [6] published the energy yearbook, showing that energy consumption in mechanical manufacturing accounted for $74.7 \%$ of the total energy consumption in the manufacturing industry. Machine tools and machining systems are numerous and widely applied, as well as are the basic energy consumption equipment in the mechanical manufacturing $[7,8]$.

A large number of studies and investigations show that the energy efficiency of the processing process is very low [9], usually less than $30 \%$ [10,11]; and Gutowski observed that the energy efficiency 
of a production line is only $14.8 \%$ [12]. In addition, Chen pointed out that machining systems possess high costs and emissions, and construct the environmentally friendly machining model and energy-aware CNC machining [13]. With wide distribution and great energy consumption and environmental pollution, machining systems possess considerable potentials for energy-saving and reducing emissions [14]. Yoon reviewed energy-saving theories and technologies towards greener machine tools and discussed general strategies on micro process planning [15]. Zhao summarized the energy consumption in machining, including classification, prediction, and reduction strategy [16]. Duflou provided a systematic overview of the state of the art in energy and resource efficiency increasing methods and techniques, having identified and summarized the systematic efficiency improving measures in the domain of discrete part manufacturing [17]. Herrmann studied the modeling and simulation of energy efficiency in the manufacturing system $[18,19]$. Kara presented an empirical model to characterize the relationship between energy consumption and process variables for material removal processes, with a predicted accuracy of more than $90 \%$ for the energy consumption of manufacturing processes [20]. Liu proposed a method for predicting energy consumption of the main driving system as a machine tool in a machining process, to provide a decision-support tool for the establishment of an energy consumption allowance, the energy-saving optimization of cutting parameters, and energy efficiency evaluation [21]. Wang presented an integrated method for assessing the energy efficiency of the machining workshop, which is helpful in providing support for machining scheme selection, energy-saving discovery and energy quota allocation in the plant [22]. Hu studied sequencing features to minimize the noncutting energy consumption in machining, considering the change of spindle rotation speed [23]. Lv developed therblig power models for calculating the energy supply to provide a reliable prediction of CNC machine tools [24]. Besides, Cai carried out a series of studies on energy benchmarking, recognized as an effective analytical methodology and management tool to improve energy efficiency and performance, and proposed energy benchmarking rules [25], energy benchmarking frameworks [26], energy modeling [27], etc., laying a crucial foundation for sustainability production.

Moreover, the CIRP manufacturing system workshop report put forward four kinds of manufacturing strategies to reduce the carbon footprint and energy consumption: Sales of products into sales of products and services, with low carbon fuel, carbon investment compensation business [28,29]. Tebaldo addressed an eco-friendly turning of Inconel 718 for both operating costs and environmental impact associated with the use, filtration and disposal of metalworking fluids [30]. Mativenga exploited a minimum energy criterion recently in the development and implementation of a methodology for the selection of optimum cutting conditions, which can minimize and hence reduce carbon dioxide emissions [31]. Zhang constructed a state space model of carbon footprint for machining processes, and researched on optimization control method for the carbon footprint of the machining process based on dynamic programming to minimize the carbon emissions [32]. Balogun researched a new mathematical model and logic for predicting direct electrical energy requirements, to track the visibility and process dependence of energy, and hence carbon footprint in the machining process [33]. Diaz introduced a strategy for the minimum energy operation of precision machining for energy savings and reduced environmental impact [34]. Andriankaja presented a new approach based on the Standard for the exchange of product model data-compliant numerical control to integrate the machining environmental assessment in the sustainable manufacturing field [35]. Masood analyzed the effect on these parameters, using face milling of titanium alloy to assess the economic factor of sustainability [36]. From the sustainability point of view of the triple bottom-line, Álvarez defined on the basis of three general dimensions: Economic, ecological and equity [37].

The above studies made an important contribution to promote the development of the conversion efficiency of machining systems, but there are also the following research gaps:

(1) The energy efficiency of machining systems is important, but the resource efficiency and waste efficiency of any machining system should also be c. If only the emphasis on energy efficiency, 
it will inevitably bring metrics tinkering leading to inaccurate and incomplete sustainability evaluation for machining systems.

(2) Machining systems involve energy, materials, services and waste in the conversion process, but how to use a unified dimension to measure, the current research is scarce.

(3) Due to the imperfect research on the evaluation index of the sustainability of machining system, the improvement method is relatively single. Therefore, it is necessary to study the evaluation index system of the sustainability of machining system with considering the economic, social and environmental benefits comprehensively.

To overcome above-mentioned problems, this study proposes an emergy-based conversion efficiency model for the machining systems that helps to improve the energy and material's utilization, and to reduce the cost and environmental emissions. The emergy theory is an eco-economic value theory and a systematic analysis method [38], which can be applied to evaluate the environmental sustainability for various types of systems [39]. Emergy is also used in the field of industrial manufacturing. For example, Sun evaluated the Chinese sectoral ecological sustainability with an emergy network [40]. The emergy sustainability index for biodiesel supply network design is employed to measure the sustainability [41]. Yang [42] also used the Emergy to evaluate a rapid infiltration system and waste treatment systems. In these conditions, the emergy of different categories can be comparable [43,44].

Therefore, emergy can measure the energy, materials, services and waste of the machining system, recognize the conversion efficiency of the machining system from the perspective of emergy, and realize the comprehensive evaluation of the economic, social and environmental benefits of the mechanical processing system. So this paper presents an emergy-based conversion efficiency model for machining systems. Our research provides both practical and academic contributions. From the theoretical significance, the ECE of the machining system is constructed to quantify the consumption yardsticks of mechanical product. It represents the emergy operating law of machining systems for establishing the real cost and system profit target of machining products. The emergy-based conversion efficiency model is a comprehensive evaluation of the efficiency of energy, material, service and waste in the process of machining systems, and clearly quantifies the economic benefit, social benefit and environmental benefit of machining systems. This evaluation model accurately characterizes the sustainable development ability of the machining systems without incomplete and metrics tinkering. It provides a theoretical and method to support the accurate measurement and improvement of the sustainability of machining systems.

With practical value, it can improve energy efficiency, material utilization and service value, reduce pollutant emissions, enhance the comprehensive efficiency of the machining systems. It can clearly tell the production operations manager how to improve the green degree and conversion efficiency of machining systems. Moreover, the most important benefit is the effective tool for planning and controlling the sustainability of machining systems. It can easily respond to the needs of the market, society and laws and regulations, and enhance the low-carbon manufacturing level of enterprises. This study provides a theory and method to improve the sustainability of the manufacturing industry.

\section{Emergy-Based Conversion Efficiency Model}

\subsection{Driver and Challenge}

In the machining system, firms usually pursue the biggest economic benefits. In fact, the biggest economic benefit is based on the inflow of the largest natural resources. This point of departure often leads to the overexploitation of natural resources and the damage of the ecological environment, resulting in the decline of the sustainability of the production systems. Machining systems are widely distributed with high-energy consumption, low efficiency and large emission. Therefore, it is of great significance to realize the sustainable machining system that can achieve resource saving, environmental friendliness and customer satisfaction. 
Sustainable machining system is the coordinated development of high-energy efficiency, less material consumption, high service efficiency and less environmental pollution for machining systems to meet customer needs with efficient conversion efficiency. Machining system is an integral system for processing metal materials into parts with a large amount of energy consumption, service consumption, resource consumption and waste emissions.

However, due to the machining machine itself, and the technical conditions and other components of the impact, the composition of consumption subject is diversity and complexity, and the process is dynamic and random. It leads to energy consumption, material consumption, service consumption and waste discharge have the characteristics of multi-link, dynamic variation, nonlinear transformation, and complex rules.

The energy, material and service consumed and wastes discharged are along with the concrete implementation and operation during the machining process. Machining system input energy, materials and services, and output products and waste. It involves economic benefits (product price), environmental benefits (environmental pollution of waste), social benefits (energy, materials purchased from other enterprises, and human resources, etc.), and is interactive in sustainable development. Therefore, How to measure the conversion efficiency with a unified precise dimension for the energy, material, service and waste of the machining system has become a challenge for evaluating and improving the sustainable machining system. The dimension of energy, material, service and waste in the machining system is different, in order to accurately and comprehensively evaluate the efficiency of energy consumption, material consumption, service consumption and waste discharge in the production process of the machining system. An emergy-based conversion efficiency model is presented to evaluate and improve for sustainable machining system. It can provide support for reducing energy consumption, improving resource efficiency and decreasing waste emissions.

\subsection{Scope and Hypothesisw}

The boundaries defined are different, and the meanings of their evaluation parameters also are different. From the machining system of energy flow, service flow, logistics and waste, this paper evaluates the sustainable machining system by emergy conversion efficiency, which is used emergy to measure the energy consumption, material consumption and service consumption, as well as emissions during the machining process within the unit production time. Emergy evaluation is used to deal with different dimensions of energy, materials, services and waste of the machining systems.

Therefore, the machining system defined for this paper refers to a variety of energy, materials, services, as well as the waste discharged that are consumed directly and indirectly in order to maintain the production of stations in the machining system. Thus, the scope and definition of the sustainable machining system are as showed in Figure 1.

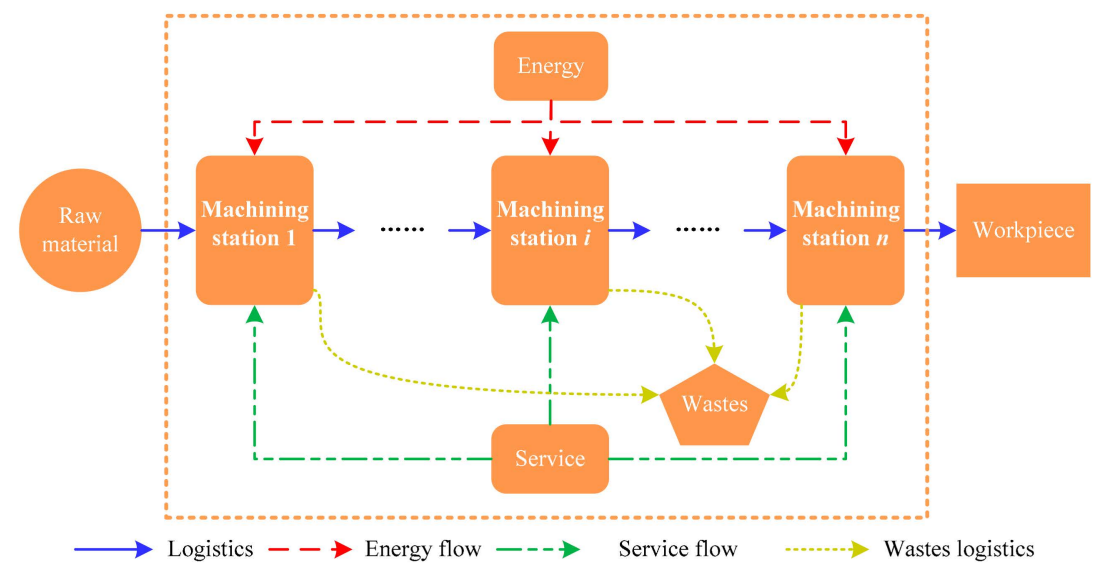

Figure 1. Boundary of sustainable machining systems. 
Hypothesis of sustainable machining systems:

- A station consists of only one machine; only one part is processed in a station's rhythm time.

- Each working procedure of a machining station can only be processed by one machine tool, and once the machining process is started; it is not allowed to be canceled or interrupted.

- The machining process can be divided into four types, including the standby, starting, idling, and machining material processes.

- Failure in manufacturing process is not considered.

- The energy, materials, services and waste are consumed in the machine shop.

\subsection{Data Collection}

There are many types of data involved in the Emergy conversion efficiency of the machining system, and the data sources are complex. The emergy-based conversion efficiency model needs a large number of basic data, especially the consumption data on energy, materials, services and wastes in the machining process, equipment and status of the machining system. Therefore, it is necessary to establish the basic database for emergy efficiency evaluation of the machining system. Prior to this, the basic database must be prepared and collected (as showed in Figure 2).

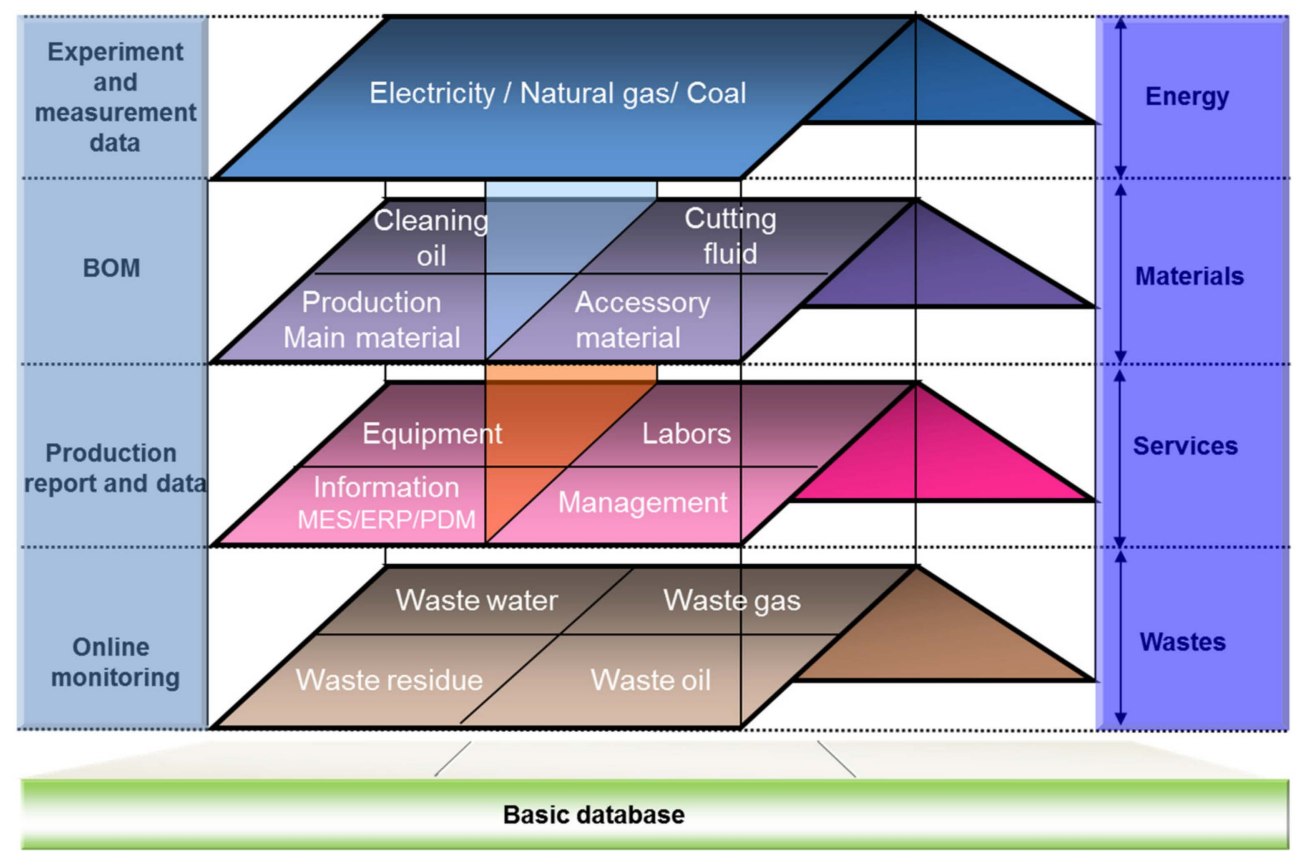

Figure 2. Basic database of machining systems.

Data acquisition is mainly through production documents, such as production plan, equipment files, logistics documents, dispatch information, and online monitoring. Online monitoring is a real-time monitoring of energy, materials and services used in processing systems and waste emissions.

\subsection{Emergy Modeling}

\subsubsection{Preparation for Emergy Theory}

Emergy is a kind of total available energy that is consumed directly or indirectly in the production process. Because different energy, resource, service and waste have different emergy values [44], emergy conversion rate is used to represent the emergy value of different classes of emergy grade system. The basic expression of emergy analysis is:

$$
E M=U E V_{i} \times N
$$


where, $E M$ is solar energy, and the unit is solar-equivalent Joule (seJ). $U E V_{i}$ is the rate of emergy conversion of different substances. $N$ is an input stream representing different units $(\mathrm{g} / \mathrm{J})$, it includes energy, materials and waste.

Emdollar value is the economic value of emergy flow, which is the concrete embodiment of emergy value in the economic market. Its expression is:

$$
E M=U E V_{c} \times U
$$

$U$ is the monetary value of economic productive activities. $U E V_{c}$ is the emergy/money ratio (unit: sej/\$).

Emergy theory can quantify various types of resources, energy, products, waste and money into a unit. The emergy of different input and output flow can be obtained by calculating. Therefore, it can be compared with the same unit in machining system with the emergy flow.

\subsubsection{Calculation Emergy of the Machining Systems}

The main energy source of the machining system is electricity, some of which are coke, natural gas, hydrogen, and diesel oil.

(1) Emergy of energy consumption

Energy is the fundamental guarantee for the operation of machining system. Energies of machining system mainly include electric, diesel oil and coke. The different energy structure of the machining system represents the different emergy consumption. The emergy calculation formula of energy consumption for the $i$-station is as follows:

$$
M N(k)^{i}=\sum_{j=1}^{m} N(k)_{j}^{i} \times U E V\left[N(k)_{j}^{i}\right]
$$

where, $k=1$ is the starting stage, $k=2$ is the standby stage, $k=3$ is the idling stage, $k=4$ is the machining stage.

$N_{j}^{i}$ is the $j$-energy source of the $i$-station.

$N(k)_{j}^{i}$ is the usage in the k-stage of $N_{j}^{i}$.

$M N(k)^{i}$ is the emergy value $N(k)_{j}^{i}$.

$U E V\left[N(k)_{j}^{i}\right]$ is emergy conversion rate of $N(k)_{j}^{i}$.

Then, the energy consumption of calculation formula of the station is as follows:

$$
M N^{i}=\sum_{k=1}^{4} M N(k)^{i}
$$

$M N^{i}$ is emergy value of energy consumption for the $i$-station in a takt time.

The application of renewable energy has better environmental friendliness and fewer emergy values. So reducing the emergy of energy consumption for the machining system can be used to replace non-renewable energy by renewable energy.

(2) Emergy of materials consumption

The essence of a machining system is to process the raw material into a mechanical product. Its production process goes hand in hand with a large amount of material consumption. The production materials of the machining system mainly include steel, alloy, cutting fluid, cleaning oil, and water. The emergy calculation formula of materials consumption for the $i$-station in the $k$-stage is as follows:

$$
M M(k)^{i}=\sum_{j=1}^{m} M(k)_{j}^{i} \times U E V\left[M(k)_{j}^{i}\right]
$$


where, $M(k)_{j}^{i}$ is the usage in the $k$-stage of $M_{j}^{i}$.

$M_{j}^{i}$ is the $j$-materials source of the $i$-station.

$M M(k)^{i}$ is the emergy value $M(k)_{j}^{i}$.

$U E V\left[M(k)_{j}^{i}\right]$ is emergy conversion rate of $M(k)_{j}^{i}$.

Then, the materials consumption calculation formula of the station is as follows:

$$
M M^{i}=\sum_{k=1}^{4} M M(k)^{i}
$$

$M M^{i}$ is emergy value of materials consumption for the $i$-station in a takt time.

(3) Emergy of services consumption

In order to maintain the production and operation of the machining system, all kinds of services are necessary. The main services include equipment, fixture, management personnel wages and welfare expenses, workshop buildings and equipment depreciation costs, rental fee, repair costs, and office expenses. So the emergy calculation formula of services consumption for the $i$-station in the $k$-stage is as follows:

$$
M S(k)^{i}=\sum_{j=1}^{m} S(k)_{j}^{i} \times U E V\left[S(k)_{j}^{i}\right]
$$

where, $S(k)_{j}^{i}$ is the usage in the k-stage of $S_{j}^{i}$.

$S_{j}^{i}$ is the $j$-services source of the $i$-station.

$M S(k)^{i}$ is the emergy value $S(k)_{j}^{i}$.

$U E V\left[S(k)_{j}^{i}\right]$ is emergy conversion rate of $M S(k)^{i}$.

Then, the services consumption calculation formula of the station is as follows:

$$
M S^{i}=\sum_{k=1}^{4} M S(k)^{i}
$$

$M S^{i}$ is emergy value of services consumption for the $i$-station in a takt time.

(4) Emergy of wastes

A lot of waste is produced in machining process. The wastes are mainly waste water, waste gas and solid waste for machining production in workshop. According to the actual needs of collection, classification, processing, packaging, handling, and storage, and sent to special processing sites formed by the waste logistics.

The emergy calculation formula of wastes for the $i$-station in the $k$-stage is as follows:

$$
M W(k)^{i}=\sum_{j=1}^{m} W(k)_{j}^{i} \times U E V\left[W(k)_{j}^{i}\right]
$$

where, $W(k)_{j}^{i}$ is the usage in the $k$-stage of $W_{j}^{i}$.

$W_{j}^{i}$ is the $j$-wastes source of the $i$-station.

$M W(k)^{i}$ is the emergy value $W(k)_{j}^{i}$.

$U E V\left[W(k)_{j}^{i}\right]$ is emergy conversion rate of $M W(k)^{i}$.

Then, the wastes calculation formula of the station is as follows:

$$
M W^{i}=\sum_{k=1}^{4} M W(k)^{i}
$$


$M W^{i}$ is emergy value of wastes for the $i$-station in a takt time.

\subsection{Establishment of Sustainable Evaluation Indexes}

Evaluation and improvement for sustainability of machining systems is important for low carbon manufacturing, and it is the key technology during the green transformation of manufacturing enterprises. Sustainability of machining systems is the coordinated development of high-energy efficiency, less material consumption, high service efficiency and less environmental pollution for machining systems to meet customer needs. In order to make a more comprehensive evaluation of the efficiency and production level of the machining system, effective emergy utilization rate (EEUR), emergy efficiency of unit product (EEUP) and emergy conversion efficiency (ECE) of the machining system are constructed to evaluate the sustainability. Based on the emergy calculation of energy, material, service and waste of machining system, they are constructed as follows.

\subsubsection{EEUR}

EEUR is equal to the system output emergy value divided by the feedback emergy from the machining system, including energy, material, service and waste. Its advantages are objective measuring the net contribution of the whole system to the economic activities, and it can evaluate the basic emergy utilization index. The size of its value can indicate the size of the emergy efficiency of the environmental resources and the economic feedback emergy in the machining process. Of course, it can be also apply to the evaluation of other industrial processes.

The effective operation is only machining stage in the mechanical process. EEUR of the machining system refers to the ratio between the effective emergy value and the total emergy consumption in the production process of the machining system.

The effective emergy value (machining stage emergy value) of the machining system is calculated as follows:

$$
M(4)=\sum_{i=1}^{n}\left[M N(4)^{i}+M M(4)^{i}+M S(4)^{i}-M W(4)^{i}\right]
$$

The reason for the negative value of $M W(4)^{i}$ is that the waste discharge is undesirable, and it is a negative impact on the effective emergy value.

The total emergy value of the system is:

$$
M=\sum_{k=1}^{4} \sum_{i=1}^{n}\left[M N(k)^{i}+M M(k)^{i}+M S(k)^{i}+M W(k)^{i}\right]
$$

Therefore, the EEUR of the machining system is calculated as follows:

$$
E m=\frac{M(4)}{M}
$$

In the same way, the EEUR of each processing station can also be deduced.

$$
e m^{i}=\frac{M(4)^{i}}{M^{i}}
$$

EEUR reflects the effective emergy efficiency directly used in the machining process. It can measure the emergy utilization efficiency of the whole system. The higher the EEUR, the more effective operation structure of mechanical processing. The machining system with a highly effective energy ratio achieves good competitiveness in production activities. It is the basic condition to achieve sustainable development for the machining system. 


\subsubsection{EEUP}

EEUP is an evaluation index to the production efficiency of the machining process, and characterizes the structural and functional rules of the ECE in the machining system (or other production systems). It provides an important measure for the rational utilization of energy, materials, services and waste of the machining system. The EEUP refers to the average emergy consumed by the machining system when producing a product. It is the ratio of the total emergy value of the machining system to the number of products, which reflect the emergy consumed by a single product. Therefore, the calculation formula of EEUP is as follows:

$$
E p=\frac{M}{N p}
$$

where, $\mathrm{M}$ is the sum of the input energy of the system. $N p=\frac{T}{t}$, it is the quantity of output. $T$ is the working time of the machining system. $t$ is the takt time of machining. The EEUP reflects emergy production efficiency of the machining system. It can be used in the horizontal and vertical comparison of the machining system, and also is one of the forms of production capacity of the machining system. The smaller the emergy efficiency of the unit product, the more the production efficiency of the systems. The index can measure the level of the sustainable development of the machining system under certain conditions, to judge the market competition ability.

\subsubsection{ECE}

ECE of the machining system is the ratio of the benefit of unit product and the total emergy value of energy, logistics, services, and waste in the production process of the machining system. It is a comprehensive measurement of the material flow, energy flow, service flow and waste logistics to support effective evaluation and improvement of sustainability the machining system, so that the system can meet the greatest ecological, economic and social benefits. It represents the comprehensive ability of the machining system, which is the quantitative embodiment of its sustainable development ability.

The formula of ECE is as follows:

$$
S=\frac{u_{p} \times N p \times U E V_{c}}{M}
$$

where, $u_{p}$ is the unit product ex-factory price, $U E V_{c}$ is Emdollar value.

ECE takes into account all the emergy used by the system, including energy, materials, services and waste, and the price of products. ECE includes economic benefits (product price), environmental benefits (environmental pollution emergy value of waste), social benefits (energy, materials purchased from other enterprises, and human resources, etc.). It takes into account the economic and social benefits that are proportional to the development goals of the machining system, also the environmental pollution that is the negative impact on the development of the system. ECE of the machining system can measure the comprehensive competitive ability of the machining system.

$S$ value is measured from the point of view of energy input and output of $t$ the machining system. The higher the $S$ value, the taller the social and economic benefits under the unit environmental pressure, and the better the sustainable development performance of the systems.

If $S=1$, it means that the social benefits, environmental benefits and economic benefits of the machining system are equivalent to the input of the system. That is to say, in terms of comprehensive benefits, the emergy value of the machining system in economic activities and the negative impact on environment and society are equal. If $S<1$, it indicates that the machining system has higher environmental pressure at an unsustainable level, the production efficiency is low. If $S>1$, it shows that the economic value of the system is greater than the negative impact on the environment and society, and indicates that the machining system is in the stage of sustainable development. 


\section{Case Study}

\subsection{Object of Analysis}

The emergy-based conversion efficiency model for machining systems is applied to a machining workshop of a vehicle bridge manufacturing enterprise (as showed in Figure 3). The enterprise mainly designs and produces semi-trailer vehicle bridge and special vehicle bridge. The production capacities of the semi-trailer vehicle bridge are 120,000 sets/year, and special vehicle bridges are 20,000 sets/year. With the scale expansion and rapid development of enterprises, the pressure of energy conservation and emission reduction policy has gradually been the focus of attention in the process of enterprise machinery processing. Therefore, how to identify, measure, evaluate and improve the sustainability of the machining production system has become an urgent problem to be resolved in enterprise operation management.

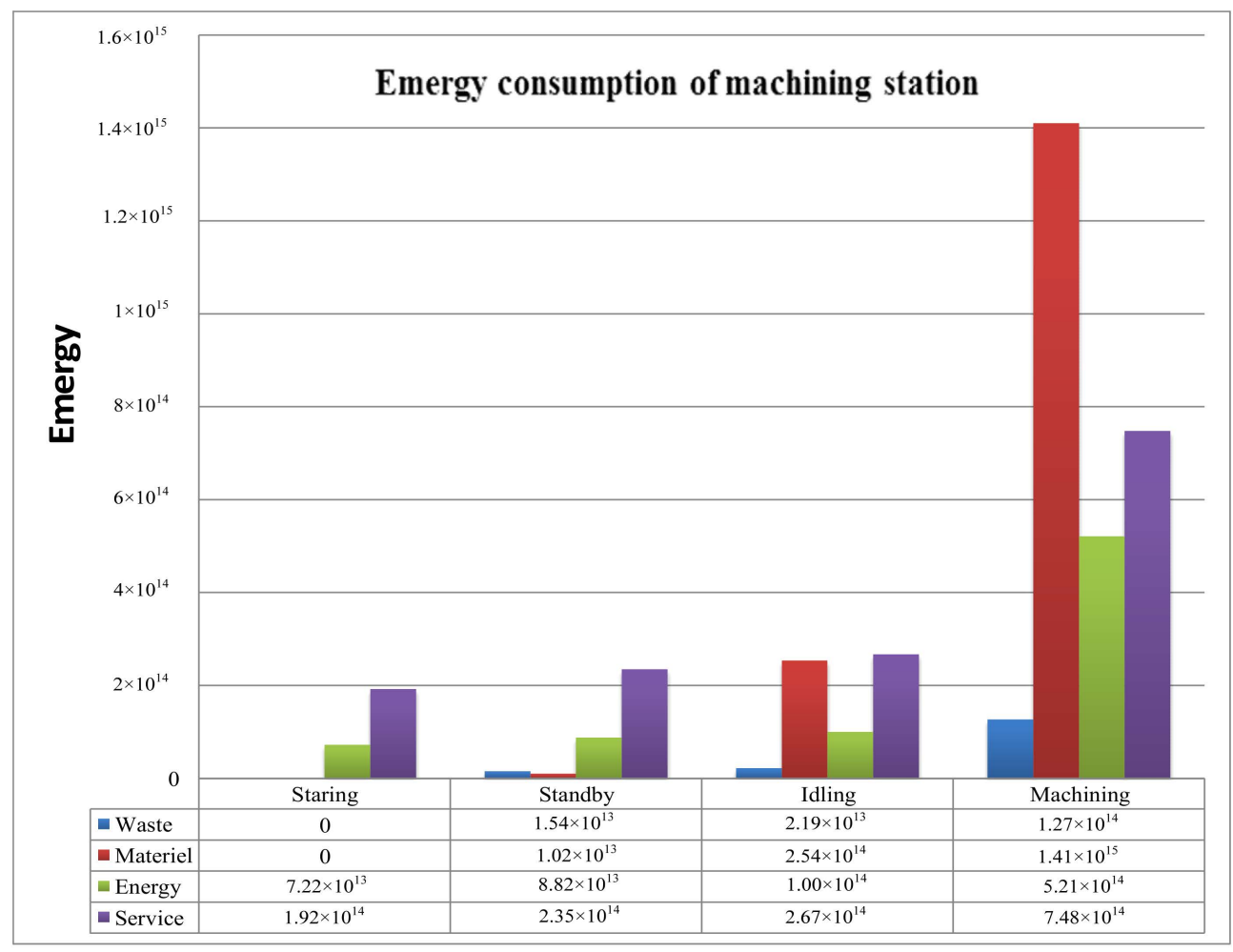

Figure 3. Emergy consumption of machining stations.

\subsection{Results}

With the active cooperation and assistance of the workshop staff, the project group collects and converts the machining workshop of semi-trailer vehicle bridge in Table 1.

Taking operating station of a FANUC machine tool as the object, the emergy consumption of the energy, materials, services and wastes in the four periods of starting, standby, idling, and machining are measured (as showed in Figure 3). 
Table 1. Emergy conversion table (unit: /day).

\begin{tabular}{|c|c|c|c|c|c|c|}
\hline $\begin{array}{c}\text { Category (Semi-Trailer Vehicle } \\
\text { Bridge) }\end{array}$ & Item & Units (Unit/a) & $\begin{array}{l}\text { Transformity } \\
\text { (Sej/Unit) }\end{array}$ & References & Raw Amount & Emergy \\
\hline \multirow{2}{*}{$\begin{array}{c}\text { Energy } \\
\text { (Energy used in machining system) }\end{array}$} & Diesel oil & $\mathrm{J}$ & $1.07 \times 10^{5}$ & [45] & $1.31 \times 10^{10}$ & $1.40 \times 10^{15}$ \\
\hline & Coke & $\mathrm{J}$ & $6.44 \times 10^{4}$ & {$[45]$} & $1.34 \times 10^{11}$ & $8.64 \times 10^{15}$ \\
\hline \multirow{10}{*}{$\begin{array}{c}\text { Materiels } \\
\text { (Materiels used in machining system) }\end{array}$} & Alloy steel & $\mathrm{g}$ & $1.96 \times 10^{10}$ & {$[43]$} & $1.75 \times 10^{6}$ & $3.43 \times 10^{16}$ \\
\hline & QT500-7 & $\begin{array}{l}8 \\
\mathrm{~g}\end{array}$ & $1.20 \times 10^{10}$ & [43] & $2.15 \times 10^{6}$ & $2.58 \times 10^{16}$ \\
\hline & Nickel & $\begin{array}{l}8 \\
\mathrm{~g}\end{array}$ & $2.00 \times 10^{10}$ & [45] & $1.85 \times 10^{3}$ & $3.69 \times 10^{13}$ \\
\hline & Titanium & $\begin{array}{l}0 \\
\mathrm{~g}\end{array}$ & $6.40 \times 10^{10}$ & [45] & $1.69 \times 10^{3}$ & $1.08 \times 10^{14}$ \\
\hline & Aluminum & $\mathrm{g}$ & $5.40 \times 10^{9}$ & [42] & $8.56 \times 10^{5}$ & $4.62 \times 10^{15}$ \\
\hline & Lubricating oil & CNY & $8.61 \times 10^{11}$ & Investigation & $3.05 \times 10^{2}$ & $2.63 \times 10^{14}$ \\
\hline & cutting fluid & $\mathrm{CNY}$ & $8.61 \times 10^{11}$ & Investigation & $6.87 \times 10^{2}$ & $5.92 \times 10^{14}$ \\
\hline & Cleaning liquid & $\mathrm{CNY}$ & $8.61 \times 10^{11}$ & Investigation & $3.97 \times 10^{2}$ & $3.42 \times 10^{14}$ \\
\hline & Water & $\mathrm{g}$ & $2.18 \times 10^{4}$ & [43] & $4.50 \times 10^{6}$ & $9.81 \times 10^{10}$ \\
\hline & Jigs and Fixtures & CNY & $8.61 \times 10^{11}$ & Investigation & $2.95 \times 10^{3}$ & $2.54 \times 10^{15}$ \\
\hline \multirow{2}{*}{$\begin{array}{c}\text { Services } \\
\text { (Services used in machining system) }\end{array}$} & Equipments & CNY & $8.61 \times 10^{11}$ & Investigation & $4.29 \times 10^{4}$ & $3.69 \times 10^{16}$ \\
\hline & Labor & CNY & $8.61 \times 10^{11}$ & [46] & $4.09 \times 10^{4}$ & $3.52 \times 10^{16}$ \\
\hline \multirow{3}{*}{$\begin{array}{c}\text { Waste } \\
\text { (Waste discharged from machining } \\
\text { system) }\end{array}$} & Waste oil disposal & CNY & $8.61 \times 10^{11}$ & [42] & $2.67 \times 10^{2}$ & $2.30 \times 10^{14}$ \\
\hline & Solid Waste & $\mathrm{g}$ & $2.52 \times 10^{8}$ & [46] & $4.89 \times 10^{4}$ & $1.23 \times 10^{13}$ \\
\hline & Waste gas & $\mathrm{g}$ & $7.24 \times 10^{8}$ & [47] & $1.86 \times 10^{4}$ & $1.35 \times 10^{13}$ \\
\hline
\end{tabular}

Note: the references for transformation of investigation are [48,49], and the emission of exhaust gas is mainly caused by dust in the process of mechanical processing [50,51]. Calculation formula of Tab 1: Transformity (sej/unit) $\times$ Raw amount = Emergy. 


\subsection{Discussions}

(1) EEUR

Based on the measurement of the emergy value of the machining workshop, the EEUR of the machining system and some the EEUR of the machining working station are shown in Figure 4 by Formulas (13) and (14).

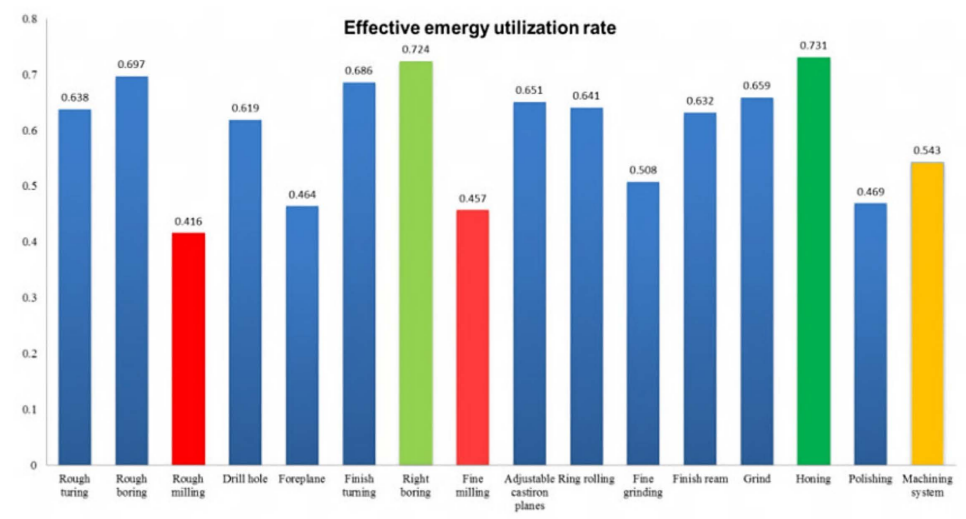

Figure 4. The EEUR of machining station.

From the EEUR of the machining system and some the EEUR of the machining working station, it is not difficult to find that the ratio of Rough milling (0.416) is the smallest, followed by Polishing $(0.457)$ and Foreplane (0.64). It shows that the emergy consumption of non-effective processing time (starting, standby and Idling) is higher, which is the object to be improved. Honing station (0.731) is the best, while the EEUR of the machining system is only 0.543 , which are at a low level.

(2) EEUP

It is known that the total emergy consumption of a working day of the machine shop is $1.88 \times 10^{17}$, and the production of the special vehicle bridge is 50 units per day. Therefore, the value of the EEUP is $3.76 \times 10^{15}$ per unit.

(3) ECE

According to the production data, the net profit of the special vehicle bridge is $4520 \mathrm{CNY}$ per unit, so the ECE can be calculated to be $S=1.03$.

The ECE of the machining system is $S>1$, indicating that the economic value of the machining system is greater than that of the negative impact on the environment and society. This means that the machining system is in a sustainable phase. However, only $S=1.03$, it says that the sustainability of the machining system has a lot of room for improvement.

(4) Improvement management of sustainability

Through the evaluation of ECE of the production system of the special vehicle bridge machine shop, we found much need to be improved. The standby time of FANUC-3-2 machine tool in Rough milling workstation is long, which leads to more consumption of energy and rail oil. The spindle and lead screw wear too fast and the product quality is unstable. It has the largest weighted entropy.

The analysis found that: FANUC-3-2 machine tool needs more than $2.5 \mathrm{~h}$ of the machine temperature every day. The spindle temperature of the natural cooling state and the spindle temperature of the processed products are inconsistent.

The thermal elongation of the spindle with the temperature of $20{ }^{\circ} \mathrm{C}$ to $85{ }^{\circ} \mathrm{C}$ is more than $0.0397 \mathrm{~mm}$ (as showed in Figure 5), which leads to unstable machining dimension and longer heating time of the machine tool.

By improving the function of the FANUC software, the elongation error of the high speed spindle is automatically detected, and then the active compensation is made. In order to achieve the maximum possible to reduce or eliminate thermal elongation error, standby time is reduced. It increased the ECE 
0.416 to 0.547 of the FANUC-3-2 machine in Rough milling station. It saved emergy for $7.82 \times 10^{14} /$ day, and the quality of machinery processing also improved $2.71 \%$.

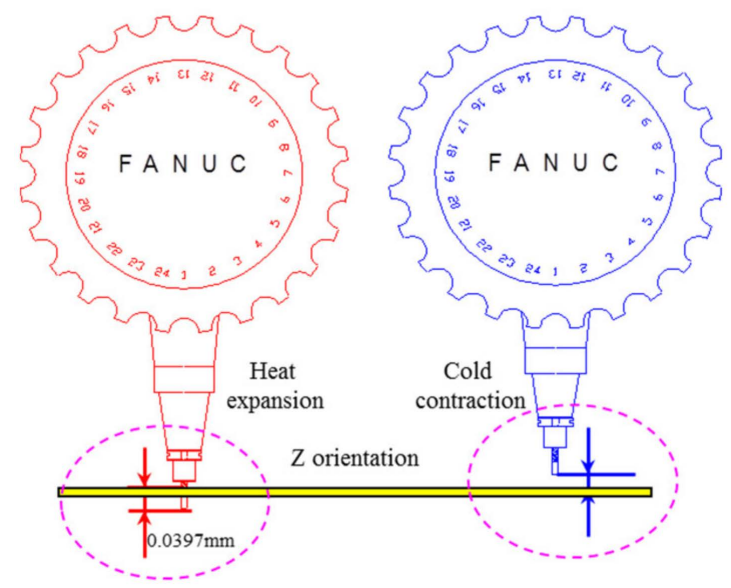

Figure 5. Thermal expansion and contraction of the spindle.

\subsection{Findings}

In order to promote the sustainability of the manufacturing system, Reference [52] has also been studied. It mainly improves the manufacturing system from the perspective of lean energy saving and emission reduction, but lacks accurate measurement model and evaluation index system, and does not discuss the conversion efficiency of the manufacturing system (as showed in Figure 6).

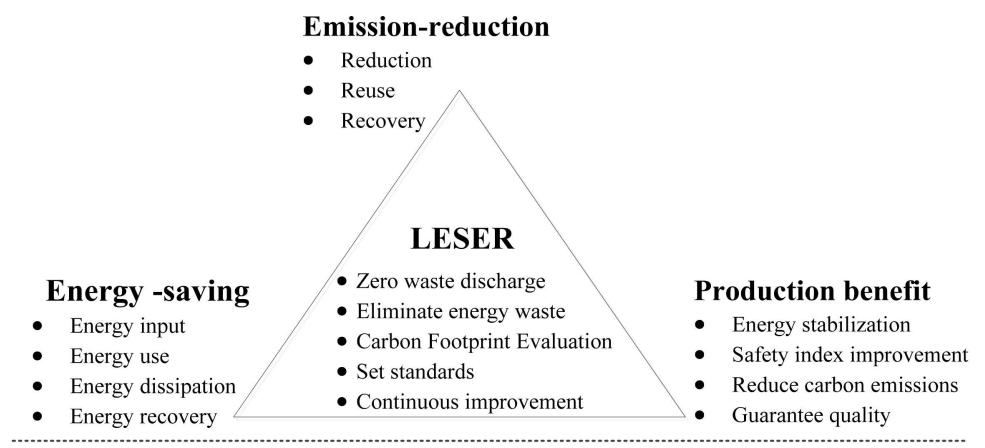

Figure 6. Promoting sustainability of manufacturing industry by LESER [51].

Compared with the sustainable measurement and evaluation of reference $[47,52]$, the method proposed in this paper has the following advantages:

First, the ECE evaluation of the machining system can clearly quantify the compensation machining products consumption scale, and measure the ability of the machining system. It is the foundation of the real value of the product (including economic value, social value and environmental value) and the profit target of the system.

Second, improvement management of ECE can improve energy efficiency, material utilization, service value, and reduce pollutant emissions. It also enhances the comprehensive efficiency of the machining system, reduces the operating cost of the system, enhances the quality of the products, and increases the green degree of the machining system. It supports a coordinated assessment model and promotion method for the sustainable development of machining systems.

Third, the most significant benefit is the effective tool for planning and controlling the sustainability of machining systems. It comprehensively measures and evaluates the economic, social and environmental benefits of the mechanical processing process. 


\section{Conclusions}

In order to improve the sustainability of machining processes, a method to realize the sustainability can be measured, evaluated and improved for the machining systems were proposed based on emergy. Firstly, previous studies on motivation and definition for sustainability of machining systems are analysed. In view of the following problems, the concept of emergy-based conversion efficiency model was proposed, which is a new tool for analysing and assessing the energy consumption, material consumption, service consumption and waste discharged in the machining process. Second, the EEUR, EEUP and ECE are constructed to evaluate the sustainability of the machining system. It is a comprehensive evaluation of the energy, material, service and waste in the machining process, and clearly measures the economic benefit, social benefit and environmental benefit of machining systems. This evaluation model accurately characterizes the sustainable development ability of the machining system without incomplete and metrics tinkering.In the process of enterprise implementation, it has some surprise and success; it is the effective tool for evaluation and improvement the sustainability of machining systems to meet the needs of the market, society and laws and regulations, and enhance the low carbon manufacturing level of enterprises.

For the improvement of the sustainability of machining systems, we will further study the optimization model and methods for the sustainability of the machining system from the point of Intelligent Control and Fault Maintenance.

Author Contributions: Conceptualisation, H.S. and C.L.; Formal analysis, J.C.; Investigation, M.G.; Visualisation, writing-review and editing, H.S., C.L. and X.S.

Funding: This research received no external funding.

Acknowledgments: This research was funded by [No. D20161801] Key projects of education department science research of Hubei Province, [No.2018kytd01] Program for Innovative Research Team in Suzhou University, [No. gxyqZD2018082] Anhui outstanding talents support program, [No. SZ2017GG28] Suzhou science and technology project, [No. 201806a02020041] Anhui Science and Technology Innovation Strategy and Soft Science Research Project, [No. KJ2018A0451, KJ2017A438] Natural Science Research Project of Anhui Education Department, and the APC was funded by [No. SZ2017ZX07] Suzhou Mechanical Equipment Co-innovation Engineering Technology Research Center.

Conflicts of Interest: The authors declare no conflict of interest.

\section{References}

1. Cai, W.; Liu, C.; Zhang, C.; Ma, M.; Rao, W.; Li, W.; He, K.; Gao, M. Developing the ecological compensation criterion of industrial solid waste based on emergy for sustainable development. Energy 2018, 157, 940-948. [CrossRef]

2. Tian, G.; Zhang, H.; Feng, Y.; Jia, H.; Zhang, C.; Jiang, Z.; Li, Z.; Li, P. Operation patterns analysis of automotive components remanufacturing industry development in China. J. Clean. Prod. 2017, 164, 1363-1375. [CrossRef]

3. Cai, W.; Liu, C.; Lai, K.-H.; Li, L.; Cunha, J.; Hu, L. Energy performance certification in mechanical manufacturing industry: A review and analysis. Energy Convers. Manag. 2019, 186, 415-432. [CrossRef]

4. Cai, W.; Liu, F.; Xie, J.; Zhou, X. An energy management approach for the mechanical manufacturing industry through developing a multi-objective energy benchmark. Energy Convers. Manag. 2017, 132, 361-371. [CrossRef]

5. Tian, G.; Zhang, H.; Feng, Y.; Wang, D.; Peng, Y.; Jia, H. Green decoration materials selection under interior environment characteristics: A grey-correlation based hybrid MCDM method. Renew. Sustain. Energy Rev. 2018, 81, 682-692. [CrossRef]

6. Liu, F.; Wang, Q.; Liu, G. Content Architecture and Future Trends of Energy Efficiency Research on Machining Systems. J. Mech. Eng. 2013, 49, 87. [CrossRef]

7. Liu, F.; Zhou, X.N.; Cai, W. The complexity and strategy for establishing product energy consumption allowance in discrete manufacturing industry. J. Mech. Eng. 2015, 10, 138-145. (In Chinese) [CrossRef]

8. Zhang, C.X. The state space model of remanufacturing carbon footprint for low-carbon. Comput. Syst. Sci. Eng. 2016, 31, 461-467. 
9. Zhou, X.N.; Liu, F.; Cai, W. An energy-consumption model for establishing energy consumption allowance of a workpiece in a machining system. J. Clean. Prod. 2016, 135, 1580-1590. [CrossRef]

10. Cai, W.; Liu, F.; Zhou, X.; Xie, J. Fine energy consumption allowance of workpieces in the mechanical manufacturing industry. Energy 2016, 114, 623-633. [CrossRef]

11. Li, L.; Deng, X.; Zhao, J.; Zhao, F.; Sutherland, J.W. Multi-objective optimization of tool path considering efficiency, energy-saving and carbon-emission for free-form surface milling. J. Clean. Prod. 2018, 172, 3311-3322.

12. Gutowski, T.G.; Branham, M.S.; Dahmus, J.B. Thermodynamic Analysis of Resources Used in Manufacturing Processes. Environ. Sci. Technol. 2009, 43, 1584-1590. [CrossRef]

13. Li, L.; Li, C.; Tang, Y.; Li, L. An integrated approach of process planning and cutting parameter optimization for energy-aware CNC machining. J. Clean. Prod. 2017, 162, 458-473. [CrossRef]

14. Hu, L.; Peng, C.; Evans, S.; Peng, T.; Liu, Y.; Tang, R.; Tiwari, A. Minimising the machining energy consumption of a machine tool by sequencing the features of a part. Energy 2017, 121, 292-305. [CrossRef]

15. Yoon, H.S.; Kim, E.S.; Kim, M.S.; Lee, J.Y.; Lee, G.B.; Ahn, S.H. Towards greener machine tools-A review on energy saving strategies and technologies. Renew. Sustain. Energy Rev. 2015, 48, 870-891.

16. Zhao, G.Y.; Liu, Z.Y.; He, Y.; Cao, H.J.; Guo, Y.B. Energy consumption in machining: Classification, prediction, and reduction strategy. Energy 2017, 133, 142-157.

17. Duflou, J.R.; Sutherland, J.W.; Dornfeld, D.; Herrmann, C.; Jeswiet, J.; Kara, S.; Hauschild, M.; Kellens, K. Towards energy and resource efficient manufacturing: A processes and systems approach. CIRP Ann. Manuf. Technol. 2012, 61, 587-609. [CrossRef]

18. Herrmann, C.; Thiede, S. Process chain simulation to foster energy efficiency in manufacturing. CIRP J. Manuf. Sci. Technol. 2009, 1, 221-229. [CrossRef]

19. Herrmann, C.; Thiede, S.; Kara, S.; Hesselbach, J. Energy oriented simulation of manufacturing systems-Concept and application. CIRP Ann. Mnnuf. Technol. 2011, 60, 45-48. [CrossRef]

20. Kara, S.; Li, W. Unit process energy consumption models for material removal processes. CIRP Ann. Mnnuf. Technol. 2011, 60, 37-40. [CrossRef]

21. Liu, F.; Xie, J.; Liu, S. A method for predicting the energy consumption of the main driving system of a machine tool in a machining process. J. Clean. Prod. 2015, 105, 171-177. [CrossRef]

22. Wang, Q.; Liu, F.; Li, C. An integrated method for assessing the energy efficiency of machining workshop. J. Clean. Prod. 2013, 52, 122-133. [CrossRef]

23. Hu, L.; Liu, Y.; Lohse, N.; Tang, R.; Lv, J.; Peng, C.; Evans, S. Sequencing the features to minimise the non-cutting energy consumption in machining considering the change of spindle rotation speed. Energy 2017, 139, 935-946. [CrossRef]

24. Lv, J.; Tang, R.; Jia, S. Therblig-based energy supply modeling of computer numerical control machine tools. J. Clean. Prod. 2014, 65, 168-177. [CrossRef]

25. Cai, W.; Liu, F.; Dinolov, O.; Xie, J.; Liu, P.; Tuo, J. Energy benchmarking rules in machining systems. Energy 2018, 142, 258-263. [CrossRef]

26. Cai, W.; Liu, F.; Xie, J.; Liu, P.; Tuo, J. A tool for assessing the energy demand and efficiency of machining systems: Energy benchmarking. Energy 2017, 138, 332-347. [CrossRef]

27. Cai, W.; Liu, F.; Zhang, H.; Liu, P.; Tuo, J. Development of dynamic energy benchmark for mass production in machining systems for energy management and energy-efficiency improvement. Appl. Energy 2017, 202, 715-725. [CrossRef]

28. Gutowski, T.G. The carbon and energy intensity of manufacturing. In Proceedings of the 40th CIRP International Manufacturing Systems Seminar, Liverpool University, Liverpool, UK, 30 May-1 June 2007.

29. Tian, G.; Zhou, M.; Li, P. Disassembly Sequence Planning Considering Fuzzy Component Quality and Varying Operational Cost. IEEE Trans. Autom. Sci. Eng. 2018, 15, 748-760. [CrossRef]

30. Tebaldo, V.; Di Confiengo, G.G.; Faga, M.G. Sustainability in machining: "Eco-friendly" turning of Inconel 718. Surface characterisation and economic analysis. J. Clean. Prod. 2017, 140, 1567-1577. [CrossRef]

31. Mativenga, P.T.; Rajemi, M.F. Calculation of optimum cutting parameters based on minimum energy footprint. CIRP Ann. Manuf. Technol. 2011, 60, 149-152. [CrossRef]

32. Zhang, C.; Liu, C.; Zhao, X. Optimization control method for carbon footprint of machining process. Int. J. Adv. Manuf. Technol. 2017, 92, 1601-1607.

33. Balogun, V.A.; Mativenga, P.T. Modelling of direct energy requirements in mechanical machining processes. J. Clean. Prod. 2013, 41, 179-186. [CrossRef] 
34. Diaz, N.; Helu, M.; Jarvis, A.; Tonissen, S.; Dornfeld, D.; Schlosser, R. Strategies for Minimum Energy Operation for Precision Machining; Laboratory for Manufacturing and Sustainability, UC Berkeley: Berkeley, CA, USA, 2009; Retrieved from https://escholarship.org/uc/item/1821r8f2.

35. Andriankaja, H.; Le Duigou, J.; Danjou, C.; Eynard, B. Sustainable machining approach for CAD/CAM/CNC systems based on a dynamic environmental assessment. Proc. Inst. Mech. Eng. Part B J. Eng. Manuf. 2016, 231, 2416-2429. [CrossRef]

36. Masood, I.; Jahanzaib, M.; Haider, A. Tool wear and cost evaluation of face milling grade 5 titanium alloy for sustainable machining. Adv. Prod. Eng. Manag. 2016, 11, 239-250. [CrossRef]

37. Álvarez, M.E.P.; Bárcena, M.M.; González, F.A. On the sustainability of machining processes. Proposal for a unified framework through the triple bottom-line from an understanding review. J. Clean. Prod. 2017, 142, 3890-3904. [CrossRef]

38. Odum, H.T. Environmental Accounting. Emergy and Environmental Decision Making; John Wiley Sons: Hoboken, NJ, USA, 1996.

39. Arbault, D.; Rugani, B.; Tiruta-Barna, L.; Benetto, E. A semantic study of the Emergy Sustainability Index in the hybrid lifecycle-emergy framework. Ecol. Indic. 2014, 43, 252-261. [CrossRef]

40. Sun, X.; An, H. Emergy network analysis of Chinese sectoral ecological sustainability. J. Clean. Prod. 2018, 174, 548-559. [CrossRef]

41. Ren, J.; Tan, S.; Yang, L.; Goodsite, M.E.; Pang, C.; Dong, L. Optimization of emergy sustainability index for biodiesel supply network design. Energy Convers. Manag. 2015, 92, 312-321. [CrossRef]

42. Yang, L.; Kong, F.L.; Xi, M.; Li, Y.; Wang, S. Environmental Economic Value Calculation and Sustainability Assessment for Constructed Rapid Infiltration System based on Emergy Analysis. J. Clean. Prod. 2017, 167, 582-588.

43. Brown, M.T.; Ulgiati, S. Assessing the global environmental sources driving the geobiosphere: A revised emergy baseline. Ecol. Model. 2016, 339, 126-132. [CrossRef]

44. Luo, Z.; Zhao, J.; Yao, R.; Shu, Z. Emergy-based sustainability assessment of different energy options for green buildings. Energy Convers. Manag. 2015, 100, 97-102. [CrossRef]

45. Pan, H.; Zhang, X.; Wu, J.; Zhang, Y.; Lin, L. Sustainability evaluation of a steel production system in China based on emergy. J. Clean. Prod. 2015, 112, 1498-1509. [CrossRef]

46. Liu, C.; Cai, W.; Dinolov, O.; Zhang, C.; Rao, W.; Jia, S.; Li, L.; Chan, F.T. Emergy based sustainability evaluation of remanufacturing machining systems. Energy 2018, 150, 670-680.

47. Liu, C.; Cai, W.; Jia, S.; Zhang, M.; Guo, H.; Hu, L.; Jiang, Z. Emergy-based evaluation and improvement for sustainable manufacturing systems considering resource efficiency and environment performance. Energy Convers. Manag. 2018, 177, 176-189. [CrossRef]

48. Liu, Z.; Liu, Y.; He, B.-J.; Xu, W.; Jin, G.; Zhang, X. Application and suitability analysis of the key technologies in nearly zero energy buildings in China. Renew. Sustain. Energy Rev. 2019, 101, 329-345. [CrossRef]

49. Jiang, Z.; Jiang, Y.; Wang, Y.; Zhang, H.; Cao, H.; Tian, G. A hybrid approach of rough set and case-based reasoning to remanufacturing process planning. J. Intell. Manuf. 2019, 30, 19-32. [CrossRef]

50. Liu, Z.; Sun, H. Review on rolling bearing axial preloaded technique of motorized spindles. China Mech. Eng. 2018, 29, 1711-1723.

51. Sun, H.M.; Liu, Z.F.; Zhou, D.; Zhan, Y.F. Research on Motorized Spindle Lifetime and Grey Prediction. J. Hefei Univ. Technol. (Nat. Sci.) 2014, 37, 257-261.

52. Cai, W.; Lai, K.H.; Liu, C.; Wei, F.; Ma, M.; Jia, S.; Jiang, Z.; Lv, L. Promoting sustainability of manufacturing industry through the lean energy-saving and emission-reduction strategy. Sci. Total Environ. 2019, 665, $23-32$.

(C) 2019 by the authors. Licensee MDPI, Basel, Switzerland. This article is an open access article distributed under the terms and conditions of the Creative Commons Attribution (CC BY) license (http://creativecommons.org/licenses/by/4.0/). 